\title{
Development of recyclable Fibre Metal Laminates (FML), their mechanical characterization and FE modelling, aiming at structural application in aeronautics
}

\author{
Stefano Bassi ${ }^{1}$, Matteo Scafe $^{2}$, Enrico Leoni ${ }^{2}$, Claudio Mingazzini ${ }^{2 *}$, Narayan Jatinder \\ Bhatia $^{3}$, Andrea Rossi ${ }^{3}$ \\ ${ }^{1}$ CNR ISTEC, 48018 Faenza RA, Italy \\ ${ }^{2}$ ENEA SSPT-PROMAS-TEMAF, 48018 Faenza RA, Italy \\ ${ }^{3}$ Consorzio MUSP, Tecnopolo di Piacenza, 29122 Piacenza PC, Italy
}

\begin{abstract}
This study concerns with the optimisation of a fibre-reinforced composite material ply book and application to an aeronautical component. The presented material solution is a recyclable FML (Fibre Metal Laminate). Recyclable and structural PMCs (Polymeric Matrix Composites) developed up-to now in ENEA had to be improved to satisfy the high-demanding fire characteristics requirements in aeronautics, particularly for the case considered in ongoing project FireMat (www.firemat.it), namely a turbine-bonnet production. FireMat project objective is the combination of weight reduction and fire resistance, maximizing the use $\mathrm{C} 2 \mathrm{C}$ recyclable, secondary and biomass derived raw materials. Aluminium layers were introduced inside the lamination, to act as oxygen barriers and improve fire-retardancy. FML were obtained starting from a fire-retardant biobased resin, which was associated with aeronautical grade basalt-derived mineral fabric, processed in the form of a prepreg and then coupled with aluminium foils. FE modelling was based on performed mechanical characterization of the single layers and interlayer adhesive strength of the ply stack: a composite sandwich structure (including aluminium honeycomb) was optimised.
\end{abstract}

\section{Introduction}

FireMat project (Emilia-Romagna Region POR FESR 2014-2020, www.firemat.it) aims to overcome the main technical limits of polymeric matrix composites (PMCs), namely fire resistance and non-recyclability. FireMat (lasting from 5/07/2019 to 4/02/2022) has been developing new materials and processes for these targets, focusing on a multi-material solution, and the related engineering to apply it to the production of aeronautical components. From another point of view, FireMat project's goals are the reinforcement of composite materials sector, overcoming the current working temperature limits of polymerbased fibre-reinforced composites; and the promotion of circular local economies by developing recyclable materials and employing secondary raw materials.

\footnotetext{
*claudio.mingazzini@enea.it; www.firemat.it
} 
The Finite Element (FE) modelling has been an important aspect to predict the performance of various design variants. The modelling played a fundamental role starting from the characterisation of material properties involved in modelling of composites until the realisation of the prototype. Inter-layer bond strength has been estimated utilising cohesive zone modelling technique [1-3].The ply book contains the stacking order, their orientation and the thicknesses of the various ply layers [4]. Precise material properties and composite ply book stack has been identified following a Design of Experiments - DOE and data matching approach on all FE models. Finally, the composite sandwich with the best possible trade-off between weight, dimensions and strength has been identified. All FE models use the commercial code Abaqus/CAE ${ }^{\odot}$ and optimisation software Isight $^{\odot}$ from Simulia $^{\odot}$. FML are hybrid structures based on alternating fibre-reinforced PMC plies and metal alloy sheets. The potential mechanical performance of FML depends on the particular nature of both composite and metal layers, metal nature and its pre-treatments, which needed to be investigated and optimized. The technical solution which is discussed in this article aims to produce "FML complex shapes" of potential interest for aeronautical applications, with the additional benefits of environmental sustainability (bio-based and partially $\mathrm{C} 2 \mathrm{C}$ recyclable composite layers), fast production of complex shapes (exploiting prepreg and aluminium layers at low thickness) and fire resistance (using the aluminium as oxygen barrier). The production of the FML was carried out starting from commercial prepregs, using a warm press. The production process might also be done by autoclave processing. Tensile tests ASTM [5] and T-peel tests [2] were performed, according to ASTM standards, in order to determine FML mechanical properties.

\section{FE Modelling}

\subsection{T-Peel test simulation}

The composite test samples have been prepared and tested by ENEA following the ASTM standard described in section 2.2. In addition, primer deposition of aluminium, resulting in an interface which increases adhesive strength between composite and aluminium layers was optimised, testing the peel resistance for adhesives [2]. Another function which is up to the interface is mediating the significant difference in thermal expansion between aluminium and composite layer. The standard size for T-peel test sample are shown in Figure 1 for a $25 \mathrm{~mm}$ wide strip where $76 \mathrm{~mm}$ is the unbounded length and $241 \mathrm{~mm}$ is the bonded length. Tests have been performed in displacement control mode maintaining a rate of $254 \mathrm{~mm} / \mathrm{min}$ and the average thickness of the interface is supposed to be $0.025 \mathrm{~mm}$.

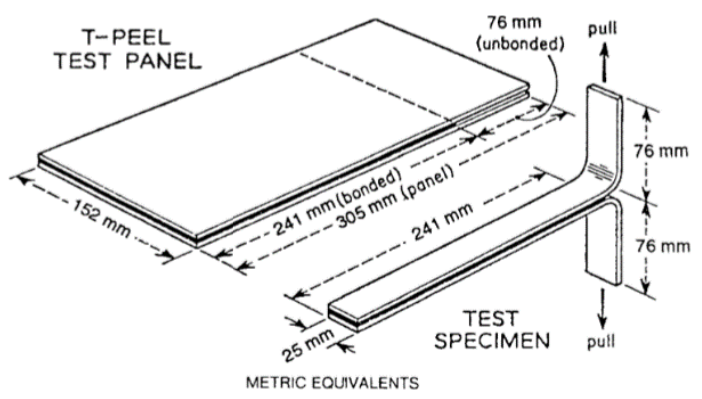

Figure 1: T-peel test specimen showing the dimensions of the adherends 
The adherends are aluminium and prepreg, with thickness 0.1 and $0.35 \mathrm{~mm}$ respectively. Cohesive zone method was used as a failure theory to model the behaviour of the interface, which acts as an adhesive layer. The crack initiation and propagation are assumed to have a mode-I failure following a traction and separation constitutive law. $T_{\max }$ is the tensile force reached after which the separation of the bond failure starts and propagates following a power law for exponential damage evolution or linear law for linear damage evolution as shown in Figure 2.

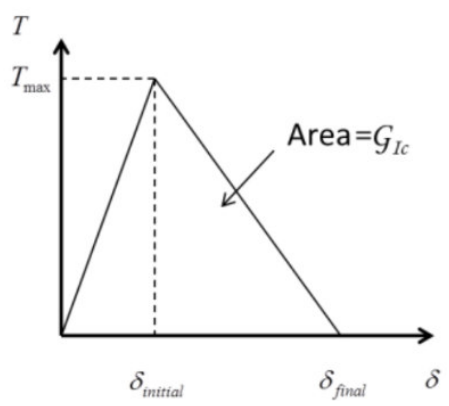

Figure 2: Traction and separation model with linear damage evolution

2D quadrilateral 4 node plane strain elements (CPE4R) have been used for the adherends whereas the cohesive layers use 4 node 2D cohesive element (COH2D4). The adherend layer has been meshed with a mesh size of $0.05 \mathrm{~mm}$ which is two times the mesh size of $0.025 \mathrm{~mm}$ for the interface layer, both having square elements. A zoom of the mesh is shown in Figure 3. The simulated and experimental deformation show good agreement in Figure 4.

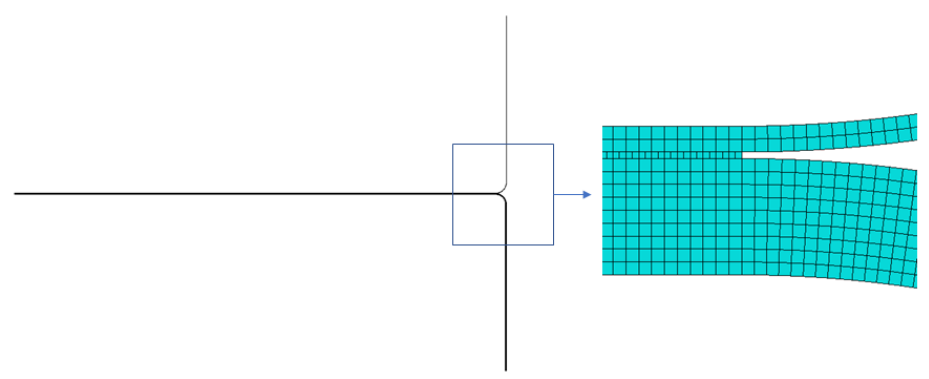

Figure 3: FE model of the T-peel specimen with details of the mesh
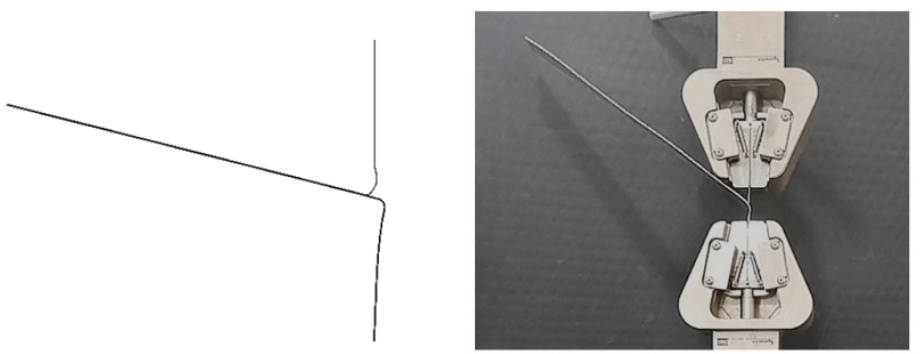

Figure 4: Comparison of the simulated (left) and experimental (right) deformation 
With the use of Isight's DOE component and data matching tool, as shown in Figure 5 in a scheme, the FE model was run multiple times to identify reasonable material properties for the adhesive layer. Fracture initiation point and average peel resistance were the two variables considered to obtain a best match curve. The result of data matching (experimental and simulated) are shown in Figure and fracture energies for mode-I failure of the interface layer in Table 1.

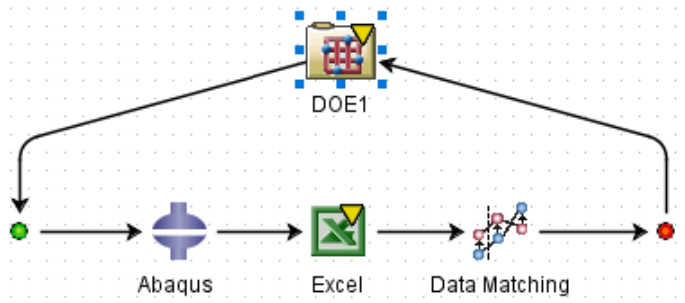

Figure 5: Scheme showing the data matching process

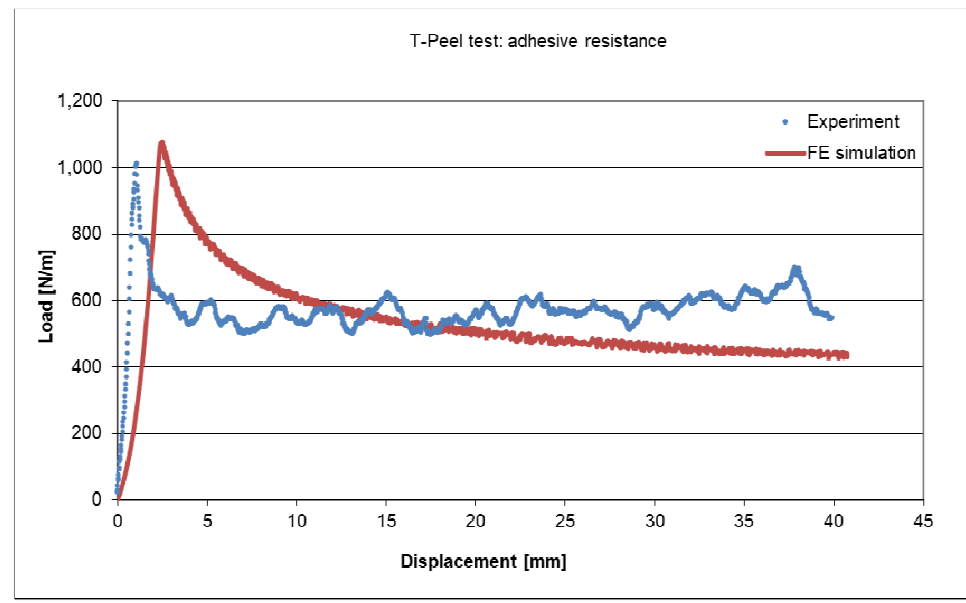

Figure 6: Adhesive resistance under Mode-1 failure. Average peel resistance measured $562 \mathrm{~N} / \mathrm{m}$ and simulated $532 \mathrm{~N} / \mathrm{mm}$

Table 1: Material properties found out for the interface layer through cohesive zone method

\begin{tabular}{|c|c|c|c|c|c|c|c|c|}
\hline \multirow{2}{*}{ Solution } & \multicolumn{3}{|c|}{$\begin{array}{c}\text { Normalised material } \\
\text { moduli }[\mathrm{MPa}]\end{array}$} & \multicolumn{3}{|c|}{$\begin{array}{c}\text { Nominal stress } \\
{[\mathrm{MPa}]}\end{array}$} & \multirow{2}{*}{$\begin{array}{c}\text { Mode-I } \\
\text { fracture } \\
\text { Energies } \\
{\left[\mathrm{KJ} / \mathbf{m}^{2}\right]}\end{array}$} & \multirow{2}{*}{$\begin{array}{c}\text { Tester } \\
\text { head } \\
\text { velocity } \\
{[\mathrm{mm} / \mathrm{s}]}\end{array}$} \\
\hline & $\mathbf{E}$ & G1 & G2 & $\begin{array}{l}\text { Normal } \\
\text { mode }\end{array}$ & $\begin{array}{c}\text { First } \\
\text { direction }\end{array}$ & $\begin{array}{l}\text { Second } \\
\text { direction }\end{array}$ & & \\
\hline 1 & 3000 & 1500 & 1500 & 17 & 22 & 22 & $\begin{array}{c}0.39 \\
0.51,0.51\end{array}$ & 2 \\
\hline 2 & 4000 & 2000 & 2000 & 17 & 22 & 22 & $\begin{array}{c}0.39 \\
0.51,0.51\end{array}$ & 4 \\
\hline 3 & 4000 & 2000 & 2000 & 23 & 25 & 25 & $\begin{array}{c}0.68 \\
0.79,0.79\end{array}$ & 4.23 \\
\hline
\end{tabular}




\subsection{Mechanical characterisations}

The mechanical properties of the materials, in term of average values, used as input for FE modelling, were obtained applying ASTM D3039 standard and are summarized in Table 2. The first step was to assess the tensile strength by means of the composite characterisation of the 0 - and 90-degrees laminations (respectively $\mathrm{C} 1$ and $\mathrm{C} 2$ ). There is a high difference between the values obtained in the two tests, due to a strong asymmetry of the starting basalt fabric, leading to a greater strength in the 0-degree direction. Once the composite characterization was completed, experimental validation of modelling on FML was carried out, by performing tensile tests. The data shown in Table 2 exhibit how different stacking affects tensile strength of obtained FML. Specifically, the samples were compared with respect to: (i) a different number of aluminium layers in stacking (FML-2 and FML-3); (ii) presence of aluminium inside or outside the laminate (FML-4 and FML-5); (iii) effect of aluminium status (FML-1 and FML-5). In general, no comparisons made show a major effect on tensile strength. However, the best choice seems to place aluminium on the outer part of the lamination to increase the fire resistance properties and to use T0 (not tempered) aluminium, in order to make it possible applying these FML also for the production of complex shapes components.

Table 2: Mechanical characterization of PMC and FML (ASTM D3039)

\begin{tabular}{|c|c|c|c|c|}
\hline Material & Orientation & $\begin{array}{c}\text { Max Stress } \\
(\mathbf{M P a})\end{array}$ & $\begin{array}{c}\text { Young's } \\
\text { Modulus (GPa) }\end{array}$ & Fracture Energy (J) \\
\hline $\mathrm{C} 1$ & $0^{\circ}$ & $650 \pm 20$ & $34.5 \pm 0.7$ & $155 \pm 5$ \\
\hline $\mathrm{C} 2$ & $90^{\circ}$ & $282 \pm 8$ & $15.5 \pm 0.4$ & $53 \pm 1$ \\
\hline $\begin{array}{c}\text { FML-1, } \mathrm{n}^{\circ} \text { composite } \\
\text { layer 5, } \mathrm{n}^{\circ} \mathrm{Al} \text { layer 2 }\end{array}$ & $0^{\circ}$ & $583 \pm 24$ & $26.0 \pm 1.7$ & $210 \pm 9$ \\
\hline $\begin{array}{c}\text { FML-2, } \mathrm{n}^{\circ} \text { composite } \\
\text { layer 4, } \mathrm{n}^{\circ} \mathrm{Al} \text { layer 2 }\end{array}$ & $0^{\circ}$ & $531 \pm 11$ & $24.9 \pm 1.0$ & $109 \pm 10$ \\
\hline $\begin{array}{c}\text { FML-3, } \mathrm{n}^{\circ} \text { composite } \\
\text { layer 4, } \mathrm{n}^{\circ} \mathrm{Al} \text { layer 5 }\end{array}$ & $0^{\circ}$ & $529 \pm 34$ & $21.2 \pm 0.8$ & $153 \pm 13$ \\
\hline $\begin{array}{c}\text { FML-4, } \mathrm{n}^{\circ} \text { composite } \\
\text { layer 5, } \mathrm{n}^{\circ} \mathrm{Al} \text { layer 2 }\end{array}$ & $0^{\circ}$ & $516 \pm 58$ & $29.1 \pm 1.5$ & $167 \pm 21$ \\
\hline $\begin{array}{c}\text { FML-5, } \mathrm{n}^{\circ} \text { composite } \\
\text { layer 5, } \mathrm{n}^{\circ} \mathrm{Al} \text { layer:2 }\end{array}$ & $0^{\circ}$ & $545 \pm 32$ & $26.1 \pm 1.6$ & $190 \pm 10$ \\
\hline
\end{tabular}

\subsection{Modelling of the composite plybook}

The helicopter engine turbine bonnet shown in Figure has been designed with the use of composite arrangements. The composite plybook was modelled as a sandwich structure composed of continuum shell membranes. The material properties found experimentally and through material characterization simulations were input in the lamina. The sandwich is composed of basalt fabric composite layer also called as the 'prepreg' layer, recycled aluminium layer and aluminium honeycomb layer. Different plybook arrangements with realizable thicknesses have been tried using the DOE technique to identify the best trade-off between strength and weight. 

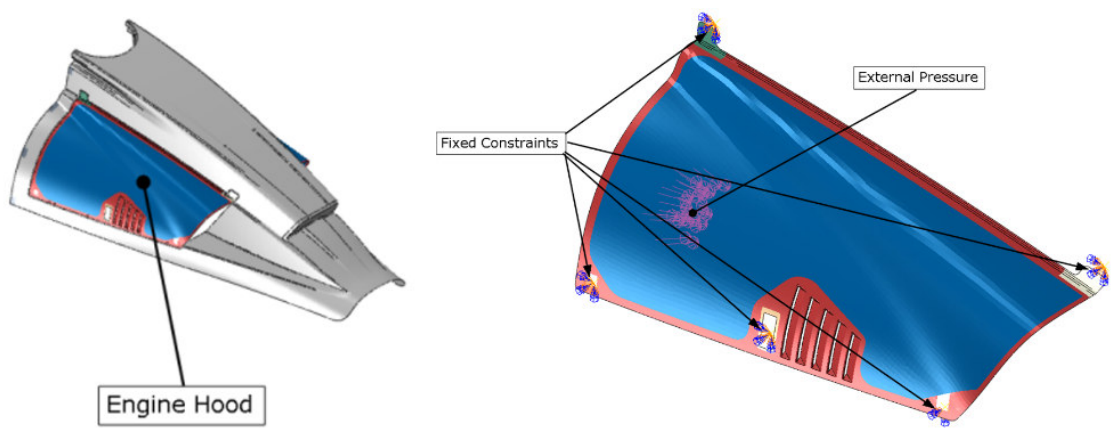

Figure 7: The turbine bonnet of the helicopter Zefhir (www.zefhir.eu), with boundary conditions and loads

The Figure shows the design variant with the use of the honeycomb layer along with its sandwich composition and structural deformation. Other ply book variants included alternate arrangements of recycled aluminium and basalt fabric layers; however, the aluminium was always kept as a surface layer for the fire-resistant properties.

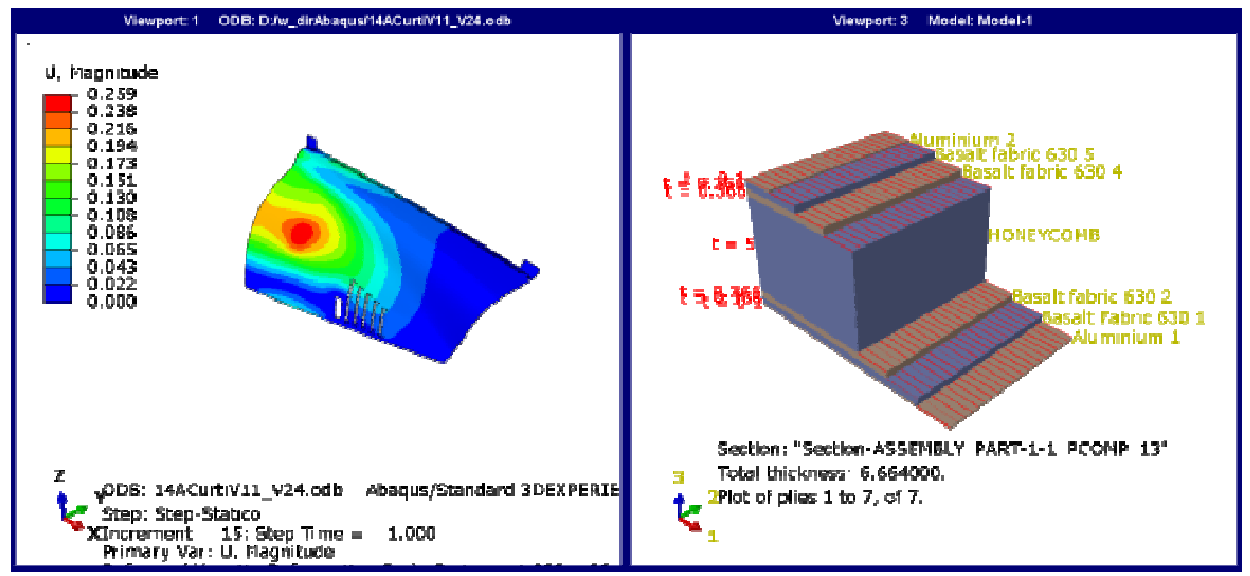

Figure 8: Considered ply book of Filava ${ }^{(}$-PFA prepreg, aluminium and honeycomb layers

\section{Helicopter turbine bonnet demonstrator}

The helicopter turbine bonnet was produced by hand-layup and then cured in autoclave, one hour at $180^{\circ} \mathrm{C}$, after vacuum bagging. Thin Aluminium in T0 state (not tempered) is used in the multi-material solution to act as a physical fire and oxidation-retardant. The processing pressure was 6 bar for the outer aesthetical surface, followed by a second curing step, including the honeycomb, at 1 bar. This double step procedure is necessary in order not to go beyond the compressive strength of the aluminium honeycomb. The prepreg was produced into the project by ENEA associating biomass-derived PFA (poly-furfuryl alcohol) fire retardant resin matrix with Filava $^{\odot}$ (Isomatex SA, Belgium) aeronautical grade mineral fibre. This prepreg is sustainable and environmentally friendly prepreg since biobased resin can be burned, although only at temperature higher than $900^{\circ} \mathrm{C}$, and Filava ${ }^{\odot}$ fibre is cradle-to-cradle recyclable, meaning it can be remelted as virgin without 
mechanical degradation, as project Cradle-to-Cradle Composites, www.c2cc-project.eu, demonstrated). Associating a fire-retardant prepreg with aluminium significantly enhances fire resistance, as it is discussed in another ICEAF VI communication from [6]. In Figure 9, the component is shown during vacuum bagging phase and after curing.
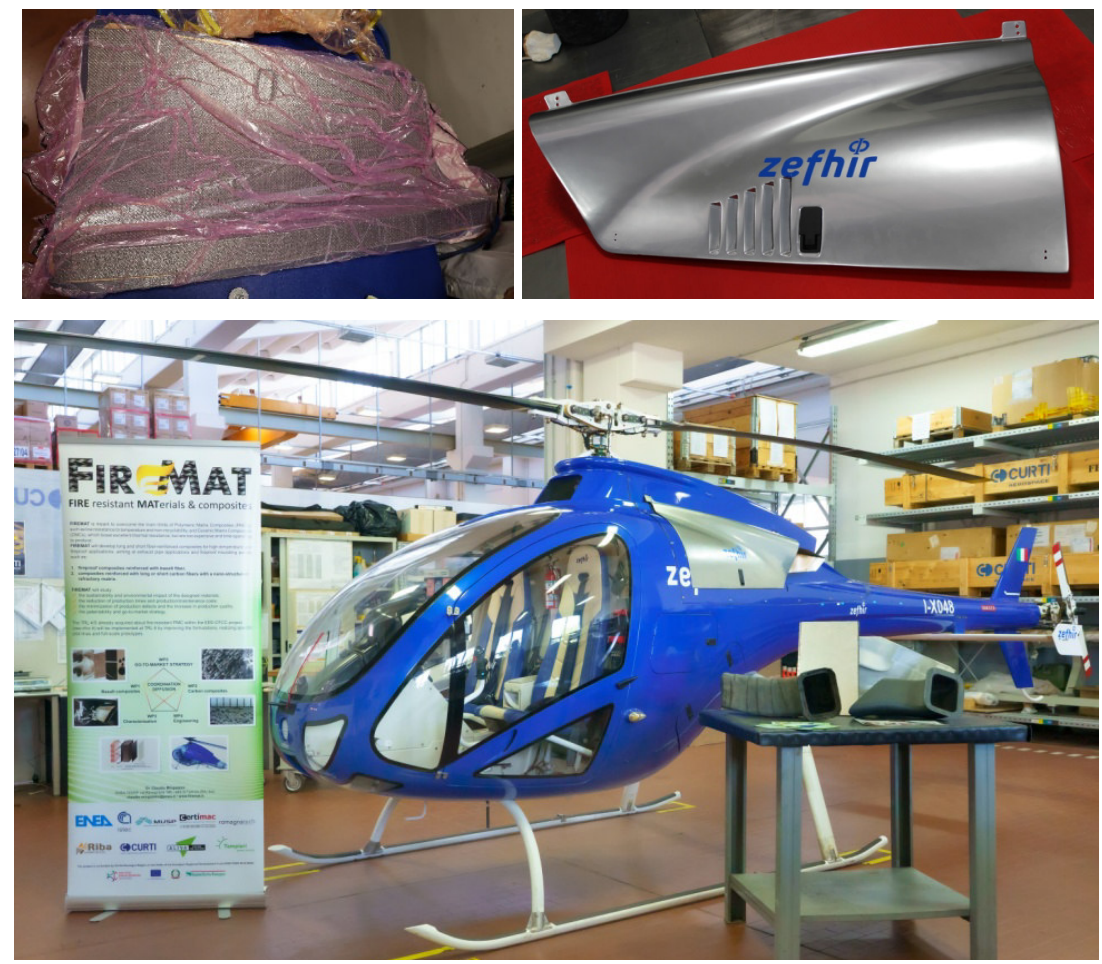

Figure 6: Lamination process and final result of the helicopter turbine bonnet

\section{Conclusion}

This study was carried out to develop a new multi-material fire-resistant solution for application in the aeronautical sector, along with applying more environmentally friendly materials and processes. The adoption of a $\mathrm{C} 2 \mathrm{C}$ recyclable mineral fibre, in association with a bio-based resin and aluminium from secondary sources make the solution very interesting in term of LCA, especially considering that fire resistant materials are generally much heavier and non-recyclable. Combining multiple innovations to achieve a single product requires a careful analysis and prediction of expected performance, aided by reliable virtual modelling. Mechanical characterization by tensile and T-peel tests were carried out for composite and the joined aluminium-composite layers. The produced data were input for the FE modelling effort to optimize the stacking of the FML, followed by the production of the FireMat project demonstrator, that is the aeronautical turbine bonnet. 


\section{References}

1. ABAQUS / Standard User's Manual, Version 2019. s.1. : Dassault Systemes Simulia Corp (2019).

2. Standard Test Method for Peel Resistance of Adhesives (T-Peel Test). ASTM D1876 (2015).

3. Finite Element Analyses of Several T-peel Specimen configurations using Cohesive Zone Models. Qian Li, Romesh Batra, David A. Dillard, and Ian Graham.

4. Finite element analysis of composite materials using Abaqus. Barbero, Ever. s.l. : CRC Press (2013).

5. Standard Test Method for Tensile Properties of Polymer Matrix Composite Materials, ASTM D3039 (2017).

6. Characterization in expected working environments of recyclable fire-resistant materials. Giulia De Aloysio, Mattia Morganti, Luca Laghi, Matteo Scafè, Enrico Leoni, Claudio Mingazzini, Stefano Bassi. ICEAF VI (2021), oral communication. 